\title{
Percepções de professores da educação básica sobre alimentação saudável e educação alimentar nutricional na escola
}

\author{
Perception of basic education teachers on healthy food \\ and food and nutritional education in school
}

Marcelo Eliseu Sipioni', Mariana Santiago Zouain', Milena Jastrow Ribett', Ana Claudia Santiago Zouain², Ana Maria Bartels Rezende

'Universidade Vila Velha - UVV/ES

¿Universidade Federal do Espírito Santo - UFES

E-mail para correspondência: Marcelo Eliseu Sipioni - mesipioni@yahoo.com.br

\begin{abstract}
Resumo
Introdução: Desde 2018, a educação alimentar e nutricional está inserida na Lei de Diretrizes e Bases da Educação, o que representa importante conquista para a promoção da alimentação saudável no ambiente escolar. Objetivo: Este estudo buscou investigar percepções acerca da educação alimentar e nutricional e do conceito de alimentação saudável e suas correlações contemporâneas com temas importantes como sustentabilidade, agricultura familiar e consumo de alimentos industrializados por professores da rede básica de ensino no município de Vila Velha-ES. Metodologia: Trata-se de um estudo transversal, descritivo com abordagem quali-quantitativa. Foi aplicado questionário semiestruturado com questões fechadas e abertas. A análise das questões fechadas se deu por estatística descritiva e as respostas às questões abertas foram analisadas de acordo com a técnica do Discurso do Sujeito Coletivo - DSC. Resultados: Todas as 16 professoras da escola abordada aceitaram participar do estudo. Os resultados demonstraram que as professoras possuem percepções limitadas a aspectos específicos das temáticas que envolvem a alimentação saudável, mesmo se aproximando do que é relevante na discussão atual. Pôde-se constatar também que as professoras consideram importante a abordagem do tema "alimentação saudável" na escola, apesar de se sentirem pouco capacitadas para tal. Conclusão: Sugere-se que esforços sejam unificados para que haja qualificação da comunidade escolar acerca da educação alimentar e nutricional, tornando-a efetivamente uma ferramenta de promoção da alimentação saudável na escola.
\end{abstract}

Palavras-chave: Educação Alimentar e Nutricional. Alimentação Saudável. Professores de Ensino fundamental.

\begin{abstract}
Introduction: Since 2018, food and nutrition education has been part of the Law of Guidelines and Bases of Education, which represents an important achievement for the promotion of healthy eating in the school environment. Objective: This study sought to investigate perceptions about food and nutrition education and the concept of healthy eating and its contemporary correlations with important
\end{abstract}


topics such as sustainability, family farming and consumption of processed foods by teachers in the basic education network in the municipality of Vila Velha-ES. Methods: This is a cross-sectional, descriptive study with a qualitative and quantitative approach. A semi-structured questionnaire with closed and open questions was applied. The analysis of closed questions was performed by descriptive statistics and the answers to open questions were analyzed according to the technique of the Collective Subject Discourse - DSC. Results: The results showed that teachers have limited perceptions of specific aspects of the themes that involve healthy eating, even approaching what is relevant in the current discussion. It was also possible to verify that the teachers consider it important to approach the theme "healthy eating" at school, despite feeling little capacity for it. Conclusion: It is suggested that efforts should be unified so that there is qualification from the school community about food and nutrition education, effectively making it a tool for promoting healthy eating at school.

Keywords: Food and Nutrition Education. Healthy eating. Elementary school teachers.

\section{INTRODUÇÃO}

A educação alimentar e nutricional (EAN) é componente fundamental das políticas de alimentação e nutrição e de segurança alimentar e nutricional (SAN) no Brasil. Através dela, busca-se a promoção da alimentação adequada e saudável (AAS) em toda a sua abrangência.

Algumas publicações elucidam como se constituiu e se desenvolveu a EAN ao longo de sua história ${ }^{1,2,3}$, variando entre ferramenta para políticas públicas e tecnicismo assistencialista. A partir dos anos 1990, quando a noção de SAN se dissemina no país, a EAN também passa a ser demandada de forma diferente, dando luz à complexidade inerente à formação dos hábitos alimentares e seus impactos na sociedade.

Atualmente, uma agenda mais ampla para a EAN busca contemplar a compreensão da AAS sobre todo o sistema alimentar, outorgando à EAN a função de discutir não só o que se come enquanto alimento. De acordo com a Política Nacional de Alimentação e Nutrição - PNAN, AAS corresponde à

“(...) prática alimentar apropriada aos aspectos biológicos e socioculturais dos indivíduos, bem como ao uso sustentável do meio ambiente. Deve estar de acordo com as necessidades de cada fase do curso da vida e com as necessidades alimentares especiais; ser referenciada pela cultura alimentar e pelas dimensões de gênero, raça e etnia; ser acessível do ponto de vista físico e financeiro; harmônica em quantidade e qualidade; baseada em 
práticas produtivas adequadas e sustentáveis; com quantidades mínimas de contaminantes físicos, químicos e biológicos" 4(67).

Desta forma, a compreensão prática da EAN demanda extrapolar o nutricionismo ${ }^{5} \mathrm{e}$ promover a AAS sob uma perspectiva abrangente. Cabe aqui salientar que tal postura exige uma ação educativa pautada no criticismo defendido por Freire ${ }^{6}$.

Para orientar os profissionais que atuam com a problemática da alimentação, foi desenvolvido o Marco de Referência de Educação Alimentar e Nutricional para as Políticas Públicas. Segundo o documento, a EAN deve considerar não só todas as fases da vida e determinantes do comportamento alimentar, como também as etapas do sistema alimentar. Além disso, o Marco considera a EAN como "campo de conhecimento e prática contínua e permanente, transdisciplinar, intersetorial e multiprofissional"3(23).

Esta passagem estabelece que o papel educativo para a promoção de hábitos alimentares saudáveis não se limita ao campo da saúde. A perspectiva ampliada do que significa a AAS advoga que todos os profissionais, agentes públicos ou não, de diferentes áreas do conhecimento e de diferentes políticas públicas são corresponsáveis nessa tarefa.

Ressalta-se aqui a importância específica da educação e dos educadores como agente educativo em alimentação e nutrição no âmbito do Programa Nacional de Alimentação Escolar - PNAE.

O PNAE estabelece que a temática da alimentação deve ser assimilada como extensão da proposta pedagógica através do estabelecido na Resolução do FNDE n 26/20137, garantindo a aplicação da EAN no processo de ensino e aprendizagem de forma transversal. Mais recentemente, a Lei 13.666/2018 ${ }^{8}$ incluiu a EAN como tema transversal na Lei de Diretrizes e Bases da Educação, dando mais destaque e pertinência à discussão aqui pretendida.

A EAN ocupa uma posição de destaque para a prevenção e o controle de diversas doenças crônicas, para a valorização dos hábitos alimentares regionais e da cultura alimentar, além de ressaltar a necessária sustentabilidade do sistema alimentar9. Além disso, possui papel gerador de informações que desempenha função de auxiliar a tomada de decisões dos indivíduos, que antes não tinham autonomia nas suas escolhas ${ }^{10}$. 
A escola é vista como o espaço ideal de promoção da saúde, uma vez que possui papel importante na formação cidadã, estimulando a autonomia, o exercício dos direitos e deveres, o controle das condições de saúde e qualidade de vida, bem como a obtenção de comportamentos e atitudes considerados saudáveis, sendo primordial para a formação de bons hábitos e escolhas ${ }^{11,12}$.

Dessa forma a promoção da AAS nas escolas possibilita impacto na saúde, estimula a autoestima, modula o comportamento e desenvolve habilidades saudáveis que são levadas para a vida dos membros da comunidade escolar. Tais atividades devem ser implementadas como temas no projeto pedagógico das escolas ${ }^{11}$.

É importante ressaltar que a formação dos hábitos alimentares é influenciada por fatores diversos, sendo iniciada na infância. É nessa fase da vida, quando o indivíduo se insere no ambiente escolar, que estará susceptível a experimentar novos alimentos, alterando seus hábitos alimentares por influências sociais nesse "novo" espaço social ${ }^{13}$. Envolver a família, a comunidade e os próprios educandos no planejamento das atividades educativas é fundamental nesse sentido, priorizando aquelas que se adequam à realidade dos sujeitos, permitindo uma melhor assimilação dos objetivos envolvidos ${ }^{14}$.

São necessárias iniciativas voltadas especialmente para a formação de profissionais que atuam em EAN, para que possam desenvolver habilidades que estejam em harmonia com as premissas atuais da AAS, assumindo caráter inovador, participativo, crítico e lúdico necessários à atividade educativa em escolas.

Assim, o objetivo deste trabalho foi investigar percepções acerca da educação alimentar e nutricional e do conceito de alimentação saudável e suas correlações contemporâneas com temas importantes como sustentabilidade, agricultura familiar e consumo de alimentos industrializados por professores da rede básica de ensino no município de Vila Velha-ES.

\section{METODOLOGIA}

Trata-se de um estudo com abordagem quali-quantitativa, descritivo e transversal, realizado em uma escola municipal de ensino fundamental de Vila Velha, Espírito Santo, Brasil, entre os meses de fevereiro e maio de 2019.

A pesquisa foi realizada com os professores de uma escola que atende a educandos do $1^{\circ}$ ao $5^{\circ}$ ano do ensino fundamental. A Unidade Escolar foi indicada pela Secretaria 
Marcelo Eliseu Sipioni, Mariana Santiago Zouain, Milena Jastrow Ribett, Ana Claudia Santiago Zouain, Ana Maria Bartels Rezende | Percepções de professores da educação básica sobre alimentação saudável e educação alimentar e nutricional na escola

Municipal de Educação de Vila Velha-ES, que também deu anuência à realização do estudo.

Para a coleta de dados, foram realizadas entrevistas semiestruturadas contendo questões adaptadas de Silva et al. $^{15}$ pela equipe de pesquisadores e testado previamente em uma escola com mesmo perfil. Para realização das entrevistas foi utilizado gravador de voz, com subsequente transcrição das respostas.

A entrevista foi composta por 25 questões organizadas em três blocos. O Bloco A correspondeu a questões fechadas sobre o perfil dos entrevistados quanto a características individuais e relacionadas ao seu trabalho, tais como idade, sexo, tempo de atividade docente e satisfação com o trabalho. O Bloco B apresentou questões abertas e fechadas sobre a percepção dos professores a respeito do tema "alimentação saudável e educação alimentar e nutricional na escola", implicando em perguntas sobre a relação entre alimentação saudável e temas como agricultura familiar, sustentabilidade, consumo de alimentos industrializados e a pertinência de se tratar o tema na escola. O Bloco C, também com questões abertas e fechadas, abordou temas inerentes à prática da EAN na escola, buscando identificar a ocorrência da abordagem do tema "alimentação" na prática docente, bem como os assuntos abordados, referências utilizadas e interação entre comunidade escolar e família.

As respostas às questões do Bloco $\mathrm{A}$ (fechadas) e as questões fechadas dos blocos $\mathrm{B} \mathrm{e}$ C foram tabuladas no software Microsoft Excel 2010, com posterior análise estatística descritiva.

As respostas às questões abertas presentes nos Blocos $\mathrm{B}$ e $\mathrm{C}$ foram transcritas e analisadas sob a perspectiva do Discurso do Sujeito Coletivo - $\mathrm{DSC}^{16}$, técnica que identifica nos discursos individuais expressões chaves que geram ideias centrais comuns entre os respondentes. A partir daí, elaboram-se discursos coletivos oriundos de atores diversos que comungam de ideias centrais semelhantes.

O trabalho foi aprovado pelo Comitê de Ética em Pesquisa com Seres Humanos (CEP) da Universidade Vila Velha - UVV/ES, sob o parecer $n^{0} 3.174 .086$, seguindo todos os princípios éticos que envolvem a pesquisa com seres humanos, incluindo o esclarecimento aos entrevistados de todas as informações necessárias sobre o estudo. 


\section{RESULTADOS}

Não houve recusa de nenhum professor em participar do estudo. Todas as participantes $(n=16)$ eram do sexo feminino e a média de idade, seu tempo de atividade como docente e seu tempo de atividade na escola estudada foram de 47,8 anos, 19 anos e 4 anos, respectivamente. Em relação ao grau de satisfação com o trabalho, quatro entrevistadas (25\%) relataram ser muito satisfeitas, oito (50\%) satisfeitas e quatro (25\%) relataram ser pouco satisfeitas.

Ao serem questionadas sobre a importância do tema "alimentação" ser tratado na escola, a maioria das entrevistadas $(14 ; 85,7 \%)$ relatou ser muito importante e duas professoras $(12,5 \%)$ entenderam ser importante.

Dentre as entrevistadas, doze $(75 \%)$ consideram que cabe à comunidade escolar promover ações de alimentação e nutrição na escola. Oito (50\%) relataram que essas ações devem ser promovidas por agentes externos à comunidade escolar, como Secretaria de Saúde. Duas professoras $(12,5 \%)$ consideram que essas ações devem ser realizadas por outros entes, como nutricionista e a família do educando. Ressalta-se que todas as entrevistadas declararam que o tema alimentação e nutrição deve ser tratado de forma transversal, em disciplinas, conteúdos e momentos na sala de aula, e não como disciplina específica.

Dez professoras $(62,5 \%)$ disseram não se sentirem capacitadas o suficiente para realizar atividades envolvendo alimentação e nutrição em sala de aula, sendo que as outras seis $(35,7 \%)$ se consideraram capacitadas para tal.

Para realização das atividades, a maioria das entrevistadas utiliza como referência principal sites ou livros, (12; 75\% e $13 ; 81,25 \%$ respectivamente), quatro (25\%) utilizam revistas e uma $(6,25 \%)$ utiliza reportagens. Após a realização das atividades, 15 (93,75\%) entrevistadas relataram perceber resultados positivos nos estudantes, incluindo a substituição de alimentos industrializados (refrigerante, biscoito recheado, "chips") por frutas nos lanches trazidos de casa. Também foi relatado pelas professoras que os alunos passam a cobrar tal postura dos familiares em suas casas e também cobram uns aos outros.

Quando questionadas sobre o conceito de alimentação saudável, pudemos identificar 4 ideias centrais em suas falas, apresentadas com seus respectivos Discursos do Sujeito Coletivo - DSC no Quadro 1. 
Marcelo Eliseu Sipioni, Mariana Santiago Zouain, Milena Jastrow Ribett, Ana Claudia Santiago Zouain, Ana Maria Bartels Rezende I Percepções de professores da educação básica sobre alimentação saudável e educação alimentar e nutricional na escola

Quadro 1 - Discursos do Sujeito Coletivo extraídos das respostas à questão "Relacione alimentação saudável e sustentabilidade" por professoras de uma Unidade de Ensino Fundamental do município de Vila Velha, Espírito Santo, Brasil, 2019.

\begin{tabular}{|c|c|c|}
\hline \multicolumn{3}{|c|}{ Questão: "Relacione alimentação saudável e sustentabilidade" } \\
\hline Ideia & Centrais (IC) & Discurso do Sujeito Coletivo \\
\hline IC 1 & Sem aprofundamento & Um puxa o outro. São temas interligados. \\
\hline IC 2 & $\begin{array}{l}\text { Desperdício e } \\
\text { reaproveitamento de } \\
\text { alimentos }\end{array}$ & $\begin{array}{l}\text { Temos que começar a repensar tanto a forma de alimentação } \\
\text { como de reaproveitar. No Brasil jogamos muitos alimentos fora, } \\
\text { acho que é o que mais joga fora no mundo. Se não criarmos } \\
\text { estratégias para aproveitar os alimentos, como as cascas de } \\
\text { frutas, por exemplo, o planeta vai entrar em colapso, porque já } \\
\text { sabemos que não tem pra todo mundo. }\end{array}$ \\
\hline IC 3 & $\begin{array}{l}\text { Preservação do meio } \\
\text { ambiente como fator } \\
\text { favorável à } \\
\text { alimentação }\end{array}$ & $\begin{array}{l}\text { Se estamos desmatando ou prejudicando o meio ambiente, } \\
\text { estamos destruindo toda a alimentação. Precisamos preservar as } \\
\text { matas, plantas, pois de lá vem nosso alimento. Se você dá uma } \\
\text { maçã para a criança comer, por exemplo, e mostra de onde veio, } \\
\text { reflete o porquê as frutas dão em épocas diferentes fazendo essa } \\
\text { ligação, mostramos porque temos que cuidar do meio ambiente. }\end{array}$ \\
\hline IC 4 & Agrotóxicos & $\begin{array}{l}\text { Porque os alimentos hoje em dia são muito contaminados. Tem a } \\
\text { questão do agrotóxico. }\end{array}$ \\
\hline IC 5 & Produção de Lixo & $\begin{array}{l}\text { Está relacionado com a higiene, limpeza das mãos antes de } \\
\text { comer, ondejogar os lixos, a questão das embalagens que poluem, } \\
\text { dos alimentos industrializados, latas de refrigerantes. Devemos } \\
\text { evitar o uso de embalagens, pois sabemos o impacto que causam } \\
\text { na natureza. Porque o ser humano não tem essa cultura de que } \\
\text { tem que jogar o lixo na lixeira para não prejudicar o meio } \\
\text { ambiente. E essa cultura nas familias de baixa renda não chegou. }\end{array}$ \\
\hline IC 6 & Hortas Domésticas & $\begin{array}{l}\text { Fazendo hortinha em casa, ter um alimento mais saudável para } \\
\text { evitar esses alimentos do mercado. }\end{array}$ \\
\hline
\end{tabular}

Fonte: autoria própria

Ao serem solicitadas a relacionarem "alimentação saudável e sustentabilidade", obtivemos um número expressivo de ideias centrais, o que pode denotar um entendimento bastante diverso sobre o tema. Contudo, pôde-se observar que nesta questão observamos respostas mais elaboradas quando comparadas às outras temáticas, com exceção de uma ideia central que demonstrou nenhuma profundidade sobre o tema.

A diversidade de entendimento sobre a relação entre alimentação saudável e sustentabilidade realmente se apresentou como elemento a ser destacado nesta pesquisa. Foram citados temas fundamentais para compor a relação solicitada, conforme Quadro 2, demonstrando que as professoras estão atentas às discussões atuais sobre preservação do meio ambiente e produção de alimentos. 
Marcelo Eliseu Sipioni, Mariana Santiago Zouain, Milena Jastrow Ribett, Ana Claudia Santiago Zouain, Ana Maria Bartels Rezende | Percepções de professores da educação básica sobre alimentação saudável e educação alimentar e nutricional na escola

Quadro 2 - Discursos do Sujeito Coletivo extraídos das respostas à questão "Relacione alimentação saudável e sustentabilidade" por professoras de uma Unidade de Ensino Fundamental do município de Vila Velha, Espírito Santo, Brasil, 2019.

\begin{tabular}{|c|c|c|}
\hline \multicolumn{3}{|c|}{ Questão: "Relacione alimentação saudável e sustentabilidade" } \\
\hline Ideia & Centrais (IC) & Discurso do Sujeito Coletivo \\
\hline IC 1 & Sem aprofundamento & Um puxa o outro. São temas interligados. \\
\hline IC 2 & $\begin{array}{l}\text { Desperdício e } \\
\text { reaproveitamento de } \\
\text { alimentos }\end{array}$ & $\begin{array}{l}\text { Temos que começar a repensar tanto a forma de alimentação } \\
\text { como de reaproveitar. No Brasil jogamos muitos alimentos fora, } \\
\text { acho que é o que mais joga fora no mundo. Se não criarmos } \\
\text { estratégias para aproveitar os alimentos, como as cascas de } \\
\text { frutas, por exemplo, o planeta vai entrar em colapso, porque já } \\
\text { sabemos que não tem pra todo mundo. }\end{array}$ \\
\hline IC 3 & $\begin{array}{l}\text { Preservação do meio } \\
\text { ambiente como fator } \\
\text { favorável à alimentação }\end{array}$ & $\begin{array}{l}\text { Se estamos desmatando ou prejudicando o meio ambiente, } \\
\text { estamos destruindo toda a alimentação. Precisamos preservar as } \\
\text { matas, plantas, pois de lá vem nosso alimento. Se você dá uma } \\
\text { maçã para a criança comer, por exemplo, e mostra da onde veio, } \\
\text { reflete o porquê as frutas dão em épocas diferentes fazendo essa } \\
\text { ligação, mostramos porque temos que cuidar do meio ambiente. }\end{array}$ \\
\hline IC 4 & Agrotóxicos & $\begin{array}{l}\text { Porque os alimentos hoje em dia são muito contaminados. Tem a } \\
\text { questão do agrotóxico. }\end{array}$ \\
\hline IC 5 & Produção de Lixo & $\begin{array}{l}\text { Está relacionado com a higiene, limpeza das mãos antes de } \\
\text { comer, onde jogar os lixos, a questão das embalagens que } \\
\text { poluem, dos alimentos industrializados, latas de refrigerantes. } \\
\text { Devemos evitar o uso de embalagens, pois sabemos o impacto } \\
\text { que causam na natureza. Porque o ser humano não tem essa } \\
\text { cultura de que tem que jogar o lixo na lixeira para não prejudicar } \\
\text { o meio ambiente. E essa cultura nas familias de baixa renda não } \\
\text { chegou. }\end{array}$ \\
\hline IC 6 & Hortas Domésticas & $\begin{array}{l}\text { Fazendo hortinha em casa, ter um alimento mais saudável para } \\
\text { evitar esses alimentos do mercado. }\end{array}$ \\
\hline
\end{tabular}

Fonte: autoria própria.

Em seguida, as professoras foram questionadas se havia relação entre alimentação saudável e agricultura familiar, de forma que todas responderam que sim. Solicitadas a comentar tal relação, obtivemos 5 ideias centrais (Quadro 3).

Quadro 3 - Discursos do Sujeito Coletivo extraídos das respostas à questão "Relacione alimentação saudável e agricultura familiar" por professoras de uma Unidade de Ensino Fundamental do município de Vila Velha, Espírito Santo, Brasil, 2019.

\begin{tabular}{|l|l|}
\hline Questão: “Relacione alimentação saudável e agricultura" \\
\hline Ideias Centrais (IC) & Discurso do Sujeito Coletivo \\
\hline $\begin{array}{l}\text { Agricultura Familiar } \\
\text { produz alimentos } \\
\text { saudáveis }\end{array}$ & $\begin{array}{l}\text { É uma coisa mais natural, livre de agrotóxicos. O pequeno } \\
\text { agricultor tenta uma agricultura mais orgânica, ele tem que ter } \\
\text { consciência de que não pode usar agrotóxicos e o que servirá } \\
\text { para ele também deve servir para o outro. }\end{array}$
\end{tabular}


Marcelo Eliseu Sipioni, Mariana Santiago Zouain, Milena Jastrow Ribett, Ana Claudia Santiago Zouain, Ana Maria Bartels Rezende | Percepções de professores da educação básica sobre alimentação saudável e educação alimentar e nutricional na escola

Continuação do quadro 3

\begin{tabular}{|c|c|c|}
\hline \multicolumn{3}{|c|}{ Questão: "Relacione alimentação saudável e agricultura" } \\
\hline Ideia & Centrais (IC) & Discurso do Sujeito Coletivo \\
\hline IC 2 & $\begin{array}{l}\text { Aproveitamento de } \\
\text { Alimentos }\end{array}$ & Há relação para aproveitamento e evitar o desperdício. \\
\hline IC 3 & $\begin{array}{l}\text { Produção de Alimentos, } \\
\text { sem aprofundar }\end{array}$ & $\begin{array}{l}\text { É através deles que temos acesso aos alimentos, às verduras. } \\
\text { Tem toda a questão de estimular o pequeno agricultor, comprar } \\
\text { em feiras, pois é ele quem produz alimentos. }\end{array}$ \\
\hline IC 4 & $\begin{array}{l}\text { Relação com } \\
\text { Alimentação Escolar }\end{array}$ & $\begin{array}{l}\text { É ela que vem para as escolas, são eles que fornecem. Para a } \\
\text { escola é mais financeiro, pois o repasse dele é muito maior, o } \\
\text { custo financeiro para escola é maior, mas não sei como isso } \\
\text { funciona. }\end{array}$ \\
\hline IC 5 & $\begin{array}{l}\text { Hortas Domésticas ou } \\
\text { Comunitárias }\end{array}$ & $\begin{array}{l}\text { Principalmente a horta em casa. Uma horta em casa, ou na } \\
\text { comunidade, é sempre melhor, pois além de ajudar sua própria } \\
\text { familia, pode ajudar outras famílias também a mudarem a } \\
\text { alimentação. Devemos estimular a criação de hortas suspensas } \\
\text { principalmente na escola para ser utilizado pelos próprios } \\
\text { alunos. }\end{array}$ \\
\hline
\end{tabular}

Fonte: autoria própria.

Em relação ao potencial prejudicial do consumo de alimentos industrializados para a saúde humana, questionamos às professoras o seguinte: "Como você avalia a relação entre o consumo de alimentos industrializados e a saúde humana?".

Neste caso, pôde-se extrair duas ideias centrais complementares. Uma associando o consumo destes alimentos a doenças crônicas. Outra referindo que tal consumo está associado à praticidade ou falta de tempo das famílias (Quadro 4).

Quadro 4 - Discursos do Sujeito Coletivo extraídos das respostas à questão "Como você avalia a relação entre o consumo de alimentos industrializados e a saúde humana?" por professoras de uma Unidade de Ensino Fundamental do município de Vila Velha, Espírito Santo, Brasil, 2019.

\begin{tabular}{|c|c|}
\hline \multicolumn{2}{|c|}{$\begin{array}{l}\text { Questão: "Como você avalia a relação entre o consumo de alimentos industrializados e a saúde } \\
\text { humana?" }\end{array}$} \\
\hline Ideias Centrais (IC) & Discurso do Sujeito Coletivo \\
\hline Causa de doenças & $\begin{array}{l}\text { Relação péssima. A gente vê pesquisas falando que o consumo } \\
\text { destes alimentos está acarretando muitas doenças nos dias atuais. } \\
\text { Tem a questão dos aditivos químicos para a conservação, gordura, } \\
\text { sódio e baixa quantidade de nutrientes trazendo muitas doenças } \\
\text { futuras, como diabetes, hipertensão e câncer, por exemplo. O ser } \\
\text { humano não tem essa cultura de se informar a respeito do que } \\
\text { consome, sem exageros. O preço disso, é o corpo reclamando } \\
\text { depois. Se consumir de vez em quando não vai prejudicar. }\end{array}$ \\
\hline $\begin{array}{ll}\text { IC } 2 & \text { Falta de } \\
\text { tempo/praticidade }\end{array}$ & $\begin{array}{l}\text { É melhor comer o que a gente faz em casa, mas por conta da } \\
\text { familia, trabalhando de mais, não tem tempo de fazer a comida } \\
\text { fresca. Pela correria a pedida é consumirmos o alimento } \\
\text { industrializado por falta de tempo. }\end{array}$ \\
\hline
\end{tabular}

Fonte: autoria própria 
Marcelo Eliseu Sipioni, Mariana Santiago Zouain, Milena Jastrow Ribett, Ana Claudia Santiago Zouain, Ana Maria Bartels Rezende | Percepções de professores da educação básica sobre alimentação saudável e educação alimentar e nutricional na escola

Quando questionadas sobre o que consideravam ser alimentação saudável para uma criança, as professoras referiram duas ideias centrais (Quadro 5). Uma delas faz relação direta entre alimentação saudável e consumo de alimentos ditos "naturais", com maior frequência de citações do consumo de Frutas, Legumes e Verduras - FLV. A segunda ideia central aponta que uma alimentação saudável está ligada ao consumo de "alimentos certos na hora certa".

Quadro 5 - Discursos do Sujeito Coletivo extraídos das respostas à questão "O que você considera alimentação saudável para uma criança?" por professoras de uma Unidade de Ensino Fundamental do município de Vila Velha, Espírito Santo, Brasil, 2019.

\begin{tabular}{|c|c|c|}
\hline Ideia & Centrais (IC) & Discurso do Sujeito Coletivo \\
\hline IC 1 & $\begin{array}{l}\text { Alimentação baseada } \\
\text { em alimentos } \\
\text { naturais, } \\
\text { especialmente FLV }\end{array}$ & $\begin{array}{l}\text { Preferir sempre os alimentos mais naturais. Descascar mais, utilizar } \\
\text { mais alimentos da feira, in natura, largar um pouco dos } \\
\text { industrializados, baseada em frutas, verduras, legumes, alimentos } \\
\text { variados, com suco natural, carnes, arroz, feijão, leite, cereais e } \\
\text { sementes também, com pouco sal e açúcar. }\end{array}$ \\
\hline IC 2 & $\begin{array}{l}\text { Alimentos certos na } \\
\text { hora certa }\end{array}$ & $\begin{array}{l}\text { É não oferecer açúcar, ter pouco sal, trigo. É se alimentar nos } \\
\text { horários certos, na hora do almoço, dar feijão e arroz, no lanche, } \\
\text { uma fruta, pela manhã um copo de leite. Porque se uma criança } \\
\text { está obesa, é porque os pais ofereceram embutidos, chips, essas } \\
\text { coisas. }\end{array}$ \\
\hline
\end{tabular}

Fonte: autoria própria.

As professoras também foram abordadas quanto à realização de atividades envolvendo o tema da alimentação e nutrição em suas atividades docentes. A maioria delas referiu utilizar as aulas de ciências para tal abordagem (10;62,5\%), sendo que dentre elas, duas também utilizam outras disciplinas. Outras 4 entrevistadas (25\%) afirmaram que abordam o tema no "dia a dia". Uma das professoras afirmou que aborda o tema apenas em momentos específicos (eventos ou comemorações na escola), e outra informou ainda não ter abordado o tema em sala de aula.

Dos subtemas abordados, o mais presente nas respostas foi "alimentos/alimentação saudável", citado por 8 professoras, seguido de FLV (6 citações). Ademais, destacase a variedade de subtemas citados pelas professoras (16, no total), podendo ser destacados assuntos como "higiene", "alimentos industrializados", "vitaminas" e "doenças causadas por alimentos".

Também foi solicitado às professoras que descrevessem um exemplo de abordagem que foi utilizada para a discussão dos subtemas relativos à alimentação e nutrição. Neste caso, foi possível identificar 10 abordagens diferentes, o que demonstra criatividade e diversidade entre as professoras. A abordagem mais citada foi a 
Marcelo Eliseu Sipioni, Mariana Santiago Zouain, Milena Jastrow Ribett, Ana Claudia Santiago Zouain, Ana Maria Bartels Rezende | Percepções de professores da educação básica sobre alimentação saudável e educação alimentar e nutricional na escola

elaboração e discussão de receitas com os alunos, presente em 7 respostas, seguida de contação de história/teatro (3 respostas).

Questionadas sobre o envolvimento das famílias nas atividades que tratam o tema alimentação e nutrição, nove professoras $(56,25 \%)$ relataram envolvimento da família nas atividades, ao passo que as outras 7 professoras $(43,75 \%)$ disseram não haver tal interação.

Em relação à interação e troca de experiência e ideias entre as professoras na abordagem do tema, onze entrevistadas $(68,75 \%)$ informaram que trocam ideias e informações com as colegas, especialmente quando se trata de turmas do mesmo ano. Outras 4 professoras (25\%) disseram não haver tal interação. Uma professora $(6,25 \%)$ disse que há interação, a depender do tema a ser abordado.

\section{DISCUSSÃO}

Os resultados encontrados nesta pesquisa demonstram que parte das professoras relacionou o tema alimentação saudável ao nível de processamento dos alimentos. Segundo elas, alimentação saudável diz respeito a priorizar alimentos in natura, conforme orientado pelo Guia Alimentar para a População Brasileira ${ }^{17}$. Contudo, dos 4 Discursos do Sujeito Coletivo - DSC elaborados, três apresentaram conceitos ainda muito relacionados ao que há de tradicional na ciência da nutrição.

Não se nega aqui a importância do consumo de frutas, verduras e legumes - FLV, da regularidade e variedade no consumo de alimentos, tampouco a importância de se consumir alimentos nutritivos. Contudo, o que constatamos é que as professoras ainda possuem conceitos limitados a certas características de uma alimentação saudável, distantes do conceito defendido pela Política Nacional de Alimentação e Nutrição - PNAN4.

Considera-se interessante também o fato de as professoras relacionarem o consumo de alimentos industrializados à saúde humana com o aumento do risco de se desenvolver doenças crônicas.

De fato, o consumo de alimentos ultraprocessados no Brasil vem aumentando nas últimas décadas ${ }^{18}$, o que eleva os riscos de diversas doenças crônicas na população brasileira ${ }^{19}$. Este alerta também está presente na $\operatorname{PNAN}^{4}$, que tem como uma de suas principais demandas a promoção da alimentação adequada e saudável (AAS) no âmbito da Saúde Pública, com vistas a reduzir carências nutricionais e doenças crônicas relacionadas aos excessos alimentares. 
Alimentos ultraprocessados podem ser identificados por características presentes especialmente na lista de ingredientes dos rótulos dos alimentos industrializados. Quando a lista de ingredientes contiver itens que não são utilizados com frequência em preparações culinárias caseiras, ou que soam estranhos aos ouvidos dos leigos, é muito provável que estamos diante de um alimento ultraprocessado. Tais itens podem ser exemplificados por emulsificantes, edulcorantes, corantes, conservantes, realçadores de sabor, antioxidantes, dentre tantos outros ${ }^{17,20}$. Vale ressaltar que nem todo alimento industrializado é ultraprocessado. Quando um alimento apresentar apenas ingredientes como sal, açúcar ou óleos comestíveis, além do alimento em si, trata-se de um alimento processado. Além disso, quando o alimento industrializado for reconhecido como tal, sem a presença de nenhum outro ingrediente (feijão em pacote, por exemplo), dizemos tratar-se de um alimento minimamente processado ${ }^{17}$.

Ressalta-se que a alimentação não está relacionada apenas à ingestão de nutrientes, mas, principalmente, aos alimentos que os contêm. Além disso, o tema relaciona-se à autonomia das pessoas nas escolhas alimentares, isto é, os indivíduos devem ter acesso a informações confiáveis sobre características e determinantes da alimentação adequada e saudável de forma a ampliar seu poder de escolha e estimulá-los a exigir o cumprimento do direito humano à alimentação adequada e saudável ${ }^{17}$.

Vale destacar que o Guia Alimentar para a População Brasileira não é direcionado apenas para uso dos profissionais de saúde enquanto instrumento educativo em alimentação e nutrição. É preciso compreender que o Guia deve ser “(...) utilizado nas casas das pessoas, nas unidades de saúde, nas escolas e em todo e qualquer espaço onde atividades de promoção da saúde tenham lugar (...)" ${ }^{17(11)}$. Em outras palavras, o Guia pode e deve ser utilizado pelas professoras como instrumento educativo em sala de aula para abordar o tema da promoção da AAS.

Referindo-se às considerações sobre a importância da alimentação saudável para uma criança, as professoras se limitaram a duas ideias centrais, com importância maior dada ao consumo de FLV.

Não se questiona a importância do consumo de FLV como parte fundamental de uma alimentação saudável, uma vez que se trata de alimentos in natura ou minimamente processados. Mas é importante destacar que tal prática precisa estar inserida em 
uma lógica habitual de consumo de outros alimentos igualmente saudáveis e importantes, como leguminosas, cereais, derivados lácteos e carnes17.

Tal demanda por diversidade alimentar foi lembrada por algumas professoras, além de outros aspectos igualmente importantes, como regularidade, redução do consumo de alimentos industrializados e redução do consumo de gorduras, sal e açúcar, o que demonstra certa consonância entre as recomendações atuais do Guia Alimentar para a População Brasileira e o que essas profissionais pensam a respeito da alimentação saudável para crianças. Além disso, estudo de Gomes, Silva e Castro ${ }^{21}$ também constatou que em domicílios onde houve aumento da aquisição de alimentos industrializados (biscoitos e refrigerantes), houve menor aumento ou decréscimo na aquisição e disponibilidade de FLV quando comparados a domicílios que não adquiriram tais alimentos industrializados.

A Sociedade Brasileira de Pediatria ${ }^{22}$ salienta que a idade escolar é o período de formação de novos laços sociais e de transição entre infância e adolescência. Por isso, transformações associadas ao processo educacional são definitivas para o aprendizado em todas as áreas e o estabelecimento de novos hábitos. A escola passa a exercer um papel significativo na manutenção da saúde física e mental da criança. Nessa fase o ganho de peso é proporcionalmente maior que o crescimento de estatura e a criança costuma modificar o seu hábito alimentar influenciada pelo meio em que vive e pela maior capacidade cognitiva e autonomia. Dessa forma, promover educação alimentar e nutricional (EAN) contribui sobremaneira no desenvolvimento de melhores hábitos alimentares.

De fato, o consumo inadequado de nutrientes pode comprometer o estado nutricional e levar ao desenvolvimento de carências ou excessos nutricionais que aumentam a vulnerabilidade das crianças a diarreias e infecções, além de poder comprometer a maturação do sistema nervoso e cognitivo ${ }^{23}$.

Salienta-se ainda que no Brasil as deficiências de ferro e vitamina A são problemas de saúde pública. Com isso, os resultados encontrados na entrevista confirmam que abordar não só FLV, mas também a influência do consumo de industrializados na saúde incentiva a escolher alimentos mais saudáveis, prevenindo o desenvolvimento das doenças crônicas e carências nutricionais que podem afetar o desenvolvimento da criança ${ }^{23}$.

Com respeito à relação entre alimentação e sustentabilidade, as professoras demonstraram correlacionar a alimentação com temas efetivamente afetos à 
sustentabilidade. Apenas uma ideia central foi considerada superficial, demonstrando um conhecimento limitado. De forma geral, temas ligados ao uso de agrotóxicos, desperdício de alimentos, produção de lixo, incentivo às hortas domésticas e necessidade de preservação do meio ambiente para garantir a produção de alimentos foram trazidos nos DSC. Ficou demonstrada a compreensão de que o alimento se origina na natureza e por isso devemos preservá-la, o que indica afinidade das professoras com os temas debatidos atualmente, apesar de, na maioria dos casos, trazerem visões limitadas a um único aspecto desta importante relação.

A relação entre alimentação e sustentabilidade é uma discussão fundamental para a promoção da AAS. Pensar alimentação saudável, sob a perspectiva da sustentabilidade, requer compreender que para que o ato alimentar aconteça é necessário que uma cadeia de processos ocorra anteriormente, desde a preparação da terra para o plantio até o acesso e consumo do alimento produzido, passando pelo cuidado da terra, colheita, transporte, distribuição e comercialização. A isso podemos denominar sistemas alimentares.

Os sistemas alimentares hegemônicos atuais são globalizados e veem o alimento sob uma perspectiva mercadológica que impõe ao meio ambiente graves danos, seja pelo uso inadequado da terra, pela exploração do trabalho no campo, pelo uso irracional da água e utilização excessiva de agentes químicos nas lavouras, especialmente adubos e agrotóxicos ${ }^{24,25,26}$.

Levando em consideração a relação entre alimentação saudável e o estímulo ao pequeno agricultor, as professoras apresentaram cinco ideias centrais diferentes, sendo que uma delas não conseguiu gerar um DSC minimamente aprofundado. As outras quatro trouxeram elementos que contribuem para o debate, mesmo demonstrando certa incipiência no entendimento das professoras sobre essa importante relação. A ideia central considerada mais relevante foi "agricultura familiar produz alimentos saudáveis". Uma outra ideia central importante a ser destacada é "relação com a alimentação escolar". Sobre estas duas teceremos alguns comentários.

Quando destacam a parceria com e escola, as professoras estão se referindo à determinação da Lei Federal 11.947/200927 que estabelece que estados e municípios devem utilizar no mínimo 30\% dos recursos repassados ao Programa Nacional de Alimentação Escolar (PNAE) pelo Fundo Nacional de Desenvolvimento da Educação 
(FNDE) para compra de produtos da agricultura familiar, o que, de fato, é uma forma de favorecer o pequeno agricultor, garantindo a ele a venda de seus produtos.

O consumo de agrotóxicos no Brasil é algo alarmante há algumas décadas ${ }^{28}$ e se acentuou muito a partir de 2019. É importante ressaltar, porém, que agricultura familiar não é sinônimo de agricultura orgânica ou agroecológica, como indicado no DSC ligado à ideia central ${ }^{1}$. Muitos agricultores familiares, por pressões do mercado de alimentos ou ausência de assistência técnica, utilizam agrotóxicos em suas lavouras como única opção. Portanto, apesar de os produtores orgânicos/agroecológicos serem, em esmagadora maioria, representantes da agricultura familiar, nem todos os agricultores familiares conseguem aderir a esta prática. Apesar disso, é na agricultura familiar que devemos depositar nossas esperanças para que no futuro a presença de alimentos agroecológicos na mesa do brasileiro seja superior aos alimentos da agricultura convencional. Práticas de sucesso a esse respeito existem em muitas localidades ${ }^{28}$.

Nenhuma professora citou o maior programa de incentivo à agricultura familiar existente no Brasil, o Programa de Aquisição de Alimentos - PAA. Tal programa, criado em 2003, estimula a compra institucional da agricultura familiar a assistir a rede socioassistencial, a rede educacional e a rede de equipamentos públicos de alimentação e nutrição ${ }^{29,30}$. Tal constatação demonstra uma importante necessidade de o PAA ser melhor divulgado pelo poder público.

Todas as professoras referiram que realizam atividades com as crianças com o tema da alimentação, sendo que os quatro subtemas mais citados foram "alimentos/alimentação saudável", "FLV", "higiene" e "alimentos industrializados". Outros subtemas surgiram com frequência inferior, remetendo, muitas vezes, a aspectos meramente biológicos relacionados à alimentação, assim como os resultados encontrados em alguns estudos ${ }^{11,31}$, sem fazer alusão às questões mais abrangentes da alimentação.

Dentre as formas de abordagem, a elaboração de receitas e contação de histórias foram as mais citadas. Contudo, não foi possível avaliarmos a execução de tais abordagens em sala de aula. Entendemos que somente com a adoção de metodologias ativas e problematizadoras seja possível encontrarmos bons resultados após as práticas educativas em alimentação e nutrição, de modo que a construção de diálogos abrangendo realidade local, que proporcionem a participação ativa e consciente dos educandos, forma cidadãos críticos, motivados, não apenas 
Marcelo Eliseu Sipioni, Mariana Santiago Zouain, Milena Jastrow Ribett, Ana Claudia Santiago Zouain, Ana Maria Bartels Rezende I Percepções de professores da educação básica sobre alimentação saudável e educação alimentar e nutricional na escola

com a conquista do seu próprio bem-estar, mas também com o de seus semelhantes9. As professoras relataram, contudo, importantes resultados após a realização das atividades, o que pode nos indicar que elas procuram problematizar o assunto, e não apenas repassá-lo de forma vertical.

O uso da internet para tratar o tema da alimentação foi citado como principal fonte de pesquisa sobre o tema, ao lado dos livros. Porém, ele requer muito cuidado e atenção. A internet se tornou uma importante aliada para facilitar o processo de ensino-aprendizagem. $\mathrm{O}$ uso deste recurso para essas atividades, contudo, gera controvérsias, sendo muitas as discussões empreendidas sobre suas vantagens e desvantagens ${ }^{32}$. Essa preocupação se agrava se a busca na internet se dirigir a influenciadores digitais no campo da alimentação ${ }^{33}$.

É fato que o uso da internet pode potencializar a necessária mudança de paradigma pedagógico, antes centrado na transmissão de saberes, na busca por um processo de ensino-aprendizado que gere situações problematizadoras, interativas e dialógicas entre educandos e educadores, sem deixar de ressaltar que tal uso deva ocorrer com muito critério ${ }^{34}$.

Em relação aos livros, cabe destacar que os próprios livros didáticos trazem elementos de alimentação e nutrição, forçados pela Lei de Diretrizes e Bases da Educação. De forma geral, alguns estudos que objetivaram analisar livros didáticos do ensino fundamental encontraram diversas limitações sobre a abordagem do tema, focando, na maioria das vezes, nas questões meramente biológicas do alimento e da alimentação, tendo como exceções algumas inserções positivas sobre segurança alimentar e nutricional, produção de alimentos e promoção da saúde $35,36,37$.

O envolvimento da família nas práticas de EAN é fundamental para que as abordagens não fiquem apenas no nível escolar. Tal envolvimento inclui, por exemplo, realizar as refeições em família, o que é orientado pelo Guia Alimentar para a População Brasileira ${ }^{17}$ e comprovadamente benéfico na formação de bons hábitos alimentares em crianças e adolescentes38. Tal constatação reforça o entendimento de que os hábitos alimentares são formados considerando-se aspectos econômicos, psicossociais, éticos, políticos e culturais ${ }^{39}$.

O comportamento alimentar tem suas bases fixadas na infância, transmitidas pela família e sustentadas por tradições, mas que ao longo da vida, esta conduta pode vir 
a se modificar em consequência de mudanças do meio, relativas à escolaridade ou relacionadas às mudanças psicológicas dos indivíduos ${ }^{40}$.

Todas as entrevistadas consideram que a EAN deva ser tratado como um conteúdo transversal nas escolas, o que também é defendido por Magalhães e Porte ${ }^{31}$, que afirmam ainda que, em nível escolar, cabe a comunidade pedagógica desenvolver ações voltadas a este assunto, não desconsiderando a importância dos outros setores, como a família e Secretaria de Saúde ou outros profissionais da área. Para tal, as professoras utilizam especialmente a disciplina de ciências, até porque o conteúdo referente a alimentação e nutrição consta nos livros desta disciplina, conforme aponta Nobre et al. ${ }^{37}$. É importante que o tema apareça em diversas disciplinas, como artes, matemática, português, história, geografia, dentre outras. Além disso, eventos que tratem do assunto devem ser realizados pela escola para que haja compartilhamento e interações de experiências das diversas turmas e faixas etárias da comunidade escolar.

O conhecimento que os professores adquirem na vida profissional são extensos e podem ser debatidos com os educandos e com outros professores, o que majoritariamente acontece, segundo relato das próprias professoras da escola estudada. Tal construção de saberes pode ocorrer tanto formalmente, em eventos, reuniões ou metodologias específicas, ou informalmente, em conversas, intervalos de aulas, ou antes de iniciarem as reuniões pedagógicas ${ }^{41}$.

No âmbito da formação de profissionais da comunidade escolar, as ações de educação permanente são realizadas por equipes intersetoriais constituídas por iniciativa das Secretarias de Educação, no âmbito do PNAE, diretamente ou por meio dos Centros Colaboradores em Alimentação e Nutrição do Escolar (CECANE). Resultados importantes têm sido alcançados, principalmente, relacionados à incorporação do tema alimentação e nutrição nos currículos e nas formações permanentes dos profissionais de educação, a um maior envolvimento da comunidade escolar com o tema da alimentação, à diversificação da alimentação ofertada aos estudantes e à aproximação entre os saberes técnico e popular³.

Um elemento importante que encontramos em nossa pesquisa foi a sensação, por parte da maioria das professoras, de que não são capacitadas para discutir questões de alimentação e nutrição com os estudantes.

Isto nos remete a um fato preocupante, pois, como lembrado por Davanço et al. $4^{0}$, a sala de aula é o ambiente propício para o processo educativo e o professor é elemento 
Marcelo Eliseu Sipioni, Mariana Santiago Zouain, Milena Jastrow Ribett, Ana Claudia Santiago Zouain, Ana Maria Bartels Rezende I Percepções de professores da educação básica sobre alimentação saudável e educação alimentar e nutricional na escola

central da equipe de saúde escolar, uma vez que tem maior contato direto com os alunos e está envolvido na realidade social e cultural dos discentes.

Nesse sentido, fica cada vez mais evidente a importância da capacitação de professores em $\mathrm{EAN}^{42}$, de forma a promover uma discussão para além do biologicismo, mas que aborde as questões complexas advindas do atual e ambicioso conceito de alimentação adequada e saudável defendido na atualidade ${ }^{11}$.

\section{CONSIDERAÇÕES FINAIS}

Buscamos identificar as percepções e práticas acerca do conhecimento de professores do ensino fundamental sobre a questão alimentar e nutricional a ser abordada nas escolas, dentro ou fora da sala de aula, com base na ideia atual de alimentação adequada e saudável (AAS) e da educação alimentar e nutricional (EAN).

Ficou evidenciado que as professoras participantes da pesquisa apresentam insegurança na abordagem do tema, ao relatarem não se sentirem qualificadas para tal. Contudo, é importante salientar que, em sua grande maioria, as profissionais demonstraram muito interesse pelo tema, seja por considerá-lo fundamental no currículo escolar ou porque consideram a alimentação saudável importante para a manutenção da saúde.

Destaca-se também que as percepções que as professoras possuem sobre conceitos que envolvem a AAS beiram ao senso comum, mas não destoam completamente da abordagem contemporânea sobre a temática. Suas respostas demonstram preocupação com o excesso de consumo de alimentos industrializados e suas consequências à saúde humana, bem como a importância da preservação do meio ambiente para a produção de alimentos. Embora essa compreensão seja otimista, a maioria delas não relacionou diretamente a alimentação saudável a outras fases do sistema alimentar, a não ser o consumo em si.

Sugere-se que estudos mais abrangentes sejam realizados com professores da rede básica de ensino para que possamos compreender mais afundo as demandas desse importante público na promoção da cidadania, incluindo aqui o consumo politizado de alimentos.

Além disso, gestores em educação e saúde devem priorizar diálogos que convirjam para a capacitação do corpo docente em tratar o tema da AAS no ambiente escolar como componente fundamental no currículo. 


\section{REFERÊNCIAS}

1. Boog MCF. Educação nutricional: passado, presente, futuro. Rev Nutr. 1997; 10(1): 5-19.

2. Lima ES. Mal de fome e não de raça: gênese, constituição e ação política da educação alimentar - Brasil: 1934-1946. Rio de Janeiro: Ed. Fiocruz; 2000.

3. Ministério do Desenvolvimento Social e Combate à Fome, Secretaria Nacional de Segurança Alimentar e Nutricional. Marco de Referência de Educação Alimentar e Nutricional para Políticas Públicas. Brasília, DF: MDS; 2012a.

4. Ministério da Saúde. Secretaria de Atenção à Saúde. Departamento de Atenção Básica. Política Nacional de Alimentação e Nutrição. Brasília, DF: MS; 2012b.

5. Pollan M. Em defesa da comida: um manifesto. Trad. Adalgisa Campos da Silva. Rio de Janeiro: Intrínseca; 2008

6. Freire P. Pedagogia da autonomia: saberes necessários a prática educativa. 37. ed. São Paulo: Paz e Terra; 1996.

7. Fundo Nacional de Desenvolvimento da Educação. Resolução ${ }^{0} 26$, de 17 de junho de 2013. Dispõe sobre o atendimento da alimentação escolar aos alunos da educação básica no âmbito do Programa Nacional de Alimentação Escolar PNAE. Diário Oficial da União. 2013.

8. Brasil. Lei 13.666, de 16 de maio de 2018. Altera a Lei $n^{0} 9.394$, de 20 de dezembro de 1996 (Lei de Diretrizes e Bases da Educação Nacional), para incluir o tema transversal da educação alimentar e nutricional no currículo escolar. Diário Oficinal da União. 2018a.

9. Ministério do Desenvolvimento Social, Secretaria Nacional de Segurança Alimentar e Nutricional. Princípios e Práticas para Educação Alimentar e Nutricional. Brasília, DF: MDS; 2018b.

10. Santos LAS. Educação alimentar e nutricional no contexto da promoção de práticas alimentares saudáveis. Rev Nutr. 2005; 18(5): 682-692.

11. Camozzi ABQ Monego ET, Menezes IHCF et al. Promoção da Alimentação Saudável na escola: realidade ou utopia? Cad Saúde Colet. 2015; 23(1):32-37.

12. Santos LAS. O fazer educação alimentar e nutricional: algumas contribuições para reflexão. Cienc Saúde Colet. 2012; 17(2): 453-462.

13. Ramos FP, Santos LAS, Reis ABC. Educação alimentar e nutricional em escolares: uma revisão de literatura. Cad Saúde Pública. 2013; 29(11):2147-2161.

14. Bizzo MLG, Leder L. Educação Nutricional nos Parâmetros Curriculares Nacionais para o Ensino Fundamental. Rev Nutr. 2005; 18(5): 661-667.

15. Silva WA, Silva WA, Santo GN. A formação do professor e a educação alimentar nas séries iniciais. Rev Educ COGEIME. 2015; 24(47): 91-109.

16. Lefèvre F. Lefèvre ANC O sujeito coletivo que fala. Interface - comunic saúde educ. 2006; 10(20):517-524.

17. Ministério da Saúde. Secretaria de Atenção à Saúde. Departamento de Atenção Básica. Guia Alimentar para a População Brasileira. 2. ed. Brasília, DF: MS; 2014. 
Marcelo Eliseu Sipioni, Mariana Santiago Zouain, Milena Jastrow Ribett, Ana Claudia Santiago Zouain, Ana Maria Bartels Rezende | Percepções de professores da educação básica sobre alimentação saudável e educação alimentar e nutricional na escola

18. Martins APB, Levy RB, Claro RM et al. Participação crescente de produtos ultraprocessados na dieta brasileira (1987-2009). Rev Saúde Pública. 2013; 47(4): 656-665.

19. Bielemann RM, Motta JVS, Minten GC et al. Consumo de alimentos ultraprocessados e impacto na dieta de adultos e jovens. Rev Saúde Pública. 2015; 49:28.

20. Monteiro CA, Cannon G, Levy RB et al. Ultra-processed foods: what they are and how to identify them. Public Health Nutr. 2019; 22(5):936-941.

21. Gomes FS, Silva GA, Castro IRR. Aquisição domiciliar de refrigerantes e biscoitos reduz o efeito de uma intervenção de promoção de frutas e hortaliças. Cad Saúde Pública. 2017; 33 (3):e00023316.

22. Sociedade Brasileira de Pediatria, Departamento de Nutrologia. Manual de orientação do departamento de nutrologia: alimentação do lactente ao adolescente, alimentação na escola, alimentação saudável e vínculo mãe-filho, alimentação saudável e prevenção de doenças, segurança alimentar. 3. ed. Rio de Janeiro: SBP; 2012.

23. Carvalho CA, Fonsêca PCA, Priore SE et al. Consumo alimentar e adequação nutricional em crianças Brasileiras: revisão sistemática. Rev Paul Pediatr. 2015; 33(3):211-221.

24. Ribeiro H, Jaime PC, Ventura D. Alimentação e sustentabilidade. Estudos Avançados. 2017; 31(89):185-198.

25. Machado PP, Oliveira NRF, Mendes AN. O indigesto sistema do alimento mercadoria. Saúde Soc. 2016; 25(2):505-515.

26. Azevedo E, Rigon SA. Sistema Alimentar com base no conceito de sustentabilidade. In: Taddei JA, Lang RMF, Longo-Silva G et al., editores. Nutrição em Saúde Pública. 2. ed. Rio de Janeiro: Rubio; 2011.

27. Brasil. Lei 11.947, de 16 de junho de 2009. Dispõe sobre o atendimento da alimentação escolar e do Programa Dinheiro Direto na Escola aos alunos da educação básica. Diário Oficinal da União. 2009.

28. Carneiro FF, Rigotto RM, AUGUSTO, LGS et al. Dossiê ABRASCO: um alerta sobre os impactos dos agrotóxicos na saúde humana. Rio de Janeiro: ESPJV/Fiocruz; São Paulo: Expressão Popular; 2015.

29. D'ávilla CR, Roversi MMS. Programa de aquisição de alimentos. In: Conti, IL, organizador. Programa de Aquisição de Alimentos: uma inovação em políticas públicas de segurança alimentar e nutricional. Passo Fundo: IFIBE; 2010.

30. Brasil. Lei $n^{0} 10.696$, de 02 de julho de 2003. Dispõe sobre a repactuação e o alongamento de dívidas oriundas de operações de crédito rural e dá outras providências. Diário Oficial da União. 2003.

31. Magalhães HSRM, Porte LHM. Percepção de educadores infantis sobre educação alimentar e nutricional. Cienc Educ. 2019. 25(1): 131-144.

32. Barreto ERL. A influência da Internet no processo ensino-aprendizagem da leitura e da escrita. Rev Espaço Acadêmico. 2010; 9:84-89.

33. Mota JJO, Almeida LC, Neves VHS et al. Análise de conteúdos de posts sobre alimentação divulgados por influenciadores digitais na rede social instagram. Demetra aliment nutr saúde. 2019; 14: e39076. 
Marcelo Eliseu Sipioni, Mariana Santiago Zouain, Milena Jastrow Ribett, Ana Claudia Santiago Zouain, Ana Maria Bartels Rezende | Percepções de professores da educação básica sobre alimentação saudável e educação alimentar e nutricional na escola

34. Coutinho CP, Alves M. Educação e sociedade da aprendizagem: um olhar sobre o potencial educativo da internet. Rev Formación Innovación Educativa Universitaria. 2010; 3(4):206-225.

35. Fiore EG, Jobstraibizer GA, SILVA CS et al. Abordagem dos temas alimentação e nutrição no material didático do ensino fundamental: interface entre segurança alimentar e nutricional e parâmetros curriculares nacionais. Saúde Soc. 2012; 21(4): 1063-1074.

36. Lima MM, Toral N. Análise dos conteúdos de alimentação e nutrição nos livros didáticos de ciências do ensino fundamental da rede pública de ensino. Demetra aliment nutr e saúde. 2020; 15:e42744.

37. Nobre LN, Oliveira RC, Gonçalves AP et al. Are textbooks tools for Food and Nutrition Educartion? Rev Assoc Bras Nutr (RASBRAN). 2018; 9(2): 43-51.

38. Tosatti AM, Ribeiro LW, Machado RHV et al. Fazer refeições em família tem efeito protetor para obesidade e bons hábitos alimentares na juventude? Revisão de 2000 a 2016. Rev. Bras. Saúde Matern Infant. 2017; 17(3):435-445.

39. Ação Brasileira pela Nutrição e Direitos Humanos - ABRANDH. O Direito Humano a Alimentação Adequada e o Sistema Nacional de Segurança Alimentar e Nutricional. Brasília, DF: ABRANDH; 2013.

40. Davanço GM, Taddei JAAC, Gaglianone CP. Conhecimentos, atitudes e práticas de professores de ciclo básico, expostos e não expostos a Curso de Educação Nutricional. Rev Nutr. 2004; 17(2):177-184.

41. Cunha ER. Os Saberes Docentes ou Saberes dos Professores. Rev Cocar. 2007; $1(2): 31-39$.

42. Silva MFG, Machado VC, Nobre LN et al. Critical collaboration in Food and Nutrition Education in schools: a methodological strategy for teacher training. Rev Assoc Bras Nutr (RASBRAN). 2018; 9(2): 52-59.

Submissão: 06/12/2020

Aprovação: 22/03/2021 